\title{
BRPKM
}
Buletin Riset Psikologi dan Kesehatan Mental http://e-journal.unair.ac.id/index.php/BRPKM e-ISSN: 2776-1851

ARTIKEL PENELITIAN

\section{Pengaruh Harga Diri dan Kesejahteraan Psikologis terhadap Celebrity Worship pada Dewasa Awal Penggemar K-pop}

\author{
NADA NUR ZAHRA \& PRIMATIA YOGI WULANDARI* \\ Departemen Psikologi Pendidikan dan Perkembangan, Fakultas Psikologi Universitas Airlangga
}

\begin{abstract}
ABSTRAK
Celebrity worship adalah fenomena normal yang terjadi akibat interaksi manusia dengan media massa, namun menjadi masalah ketika seseorang menjadi terobsesi dengan satu atau lebih selebriti. Penelitian ini bertujuan untuk mengetahui apakah terdapat pengaruh harga diri dan kesejahteraan psikologis terhadap celebrity worship pada dewasa awal penggemar K-pop di Surabaya. Penelitian ini menggunakan pendekatan kuantitatif dengan melibatkan 121 partisipan berusia 18-25 tahun. Skala yang digunakan pada penelitian ini adalah RSES, PWBS, dan CAS. Data dianalisis dengan IBM SPSS Statistics Version 25 for Windows dan Jamovi 1.6.15. Hasil penelitian ini menunjukkan bahwa harga diri dan kesejahteraan psikologis secara simultan dan parsial tidak memiliki pengaruh signifikan terhadap celebrity worship intense-personal dan borderline-pathological (sig $>0,05$ ). Dapat disimpulkan bahwa harga diri dan kesejahteraan psikologis tidak berpengaruh terhadap celebrity worship.
\end{abstract}

Kata kunci: celebrity worship, harga diri, kesejahteraan psikologis

\begin{abstract}
Celebrity worship is a normal phenomenon caused by human interaction with mass media, but it become a problem when a person become obsessed with one or more celebrities. This research aims to determine whether there are influence of Self-Esteem and Psychological Well-Being on Celebrity Worship among Emerging Adult K-pop Fans at Surabaya. This research uses quantitative approach involving 121 participants around 18-25 years old. The scales used in this research are RSES, PWBS, and CAS. The data was analyzed by IBM SPSS Statistics Version 25 for Windows and Jamovi 1.6.15. The results of this research show that self-esteem and psychological well-being simultaneously and partially have no significant effect on celebrity worship intense-personal and borderline-pathological $(\operatorname{sig}>0,05)$. In conclusion, self-esteem and psychological well-being have no effect on celebrity worship.
\end{abstract}

Keywords: celebrity worship, psychological well-being, self-esteem

Buletin Penelitian Psikologi dan Kesehatan Mental (BRPKM), 2021, Vol. 1(1), 1115-1125

*Alamat korespondensi: Fakultas Psikologi Universitas Airlangga, Kampus B Universitas Airlangga Jalan Airlangga 4-6 Surabaya 60286. Surel: primatia.yogi@psikologi.unair.ac.id 


\section{PENDAHULUAN}

Fenomena kepopuleran hiburan yang berasal dari negeri Korea Selatan seperti kepopuleran musik atau drama, bukan merupakan hal yang baru di Indonesia. Fenomena yang akrab disebut sebagai Korean wave atau hallyu wave ini pada mulanya menyebar ke negeri China, Taiwan, dan Hong Kong. Setelah menyebar ke negara-negara terdekat dengan Korea Selatan, akhirnya pada tahun 2000 dunia hiburan Korea Selatan mulai memasuki pasar Asia Tenggara termasuk ke Indonesia (Shim, 2006). Perkembangan kepopuleran Korean Wave didukung juga oleh kemunculan musik dari Korea Selatan atau biasa disebut dengan Korean Pop atau K-pop. K-pop berhasil menarik banyak penggemar terutama dari kalangan anak muda di Indonesia. Kesuksesan K-pop di Indonesia dapat dilihat dari adanya berbagai acara berkaitan dengan K-pop di Indonesia dari tahun ke tahun seperti acara konser yang mengundang selebriti K-pop dan acara perkumpulan penggemar (fan gathering) yang mencapai 120 acara pada tahun 2010 (Jung, 2011).

Interaksi manusia dengan media massa dalam kehidupan sehari-hari menjadikan aktivitas menggemari selebriti menjadi suatu fenomena yang normal terjadi, tak terkecuali kegemaran masyarakat Indonesia terhadap selebriti Korea Selatan atau selebriti K-pop. Selebriti hadir di media massa sebagai hiburan bagi penontonnya (McCutcheon, Maltby, dan Ashe, 2004 dalam Rojek, 2012). Kegemaran pada selebriti menjadi bermasalah jika individu yang awalnya melihat selebriti sebagai hiburan semata kemudian menjadi terobsesi dengan selebriti. Fenomena dimana individu menjadi terobsesi pada selebriti disebut dengan celebrity worship (Maltby dkk., 2003). Celebrity worship dapat didefinisikan sebagai rentang kontinum dimana individu menjadi terobsesi pada selebriti. Celebrity worship terdiri dari 3 tahapan kontinum yaitu: (1) Entertainment-social, dimana penggemar menyukai selebriti karena kemampuan selebriti untuk menghibur (2) Intense-personal, tahap dimana individu mulai obsesif dan tidak bisa berhenti memikirkan selebriti (3) Borderline-pathological, tahap patologis dimana penggemar rela melakukan apa saja termasuk tindakan ilegal dan menghabiskan uang belasan juta rupiah untuk selebriti favoritnya (Maltby dkk., 2003).

Dewasa awal seharusnya sudah dapat menyeleksi aktivitasnya dimana mereka tetap fokus pada kegiatan sehari-hari dan selebriti hanya untuk tujuan relaksasi saja. Namun, pada kenyataannya hingga kini orang dewasa masih banyak yang terobsesi dan menjadikan selebriti sebagai hal paling dominan di hidupnya (Giles, 2000 dalam Mccutcheon, dkk., 2002). Widjaja \& Ali (2015) menemukan bahwa penggemar K-pop di Jakarta berusia 20-30 tahun sebanyak 34,8\% berada pada tahap intense-personal. Pada penelitian ini, penulis juga melakukan preliminary study untuk melihat fenomena celebrity worship pada populasi yang akan diteliti yaitu penggemar K-pop di Surabaya. Dari hasil preliminary study pada 132 partisipan ditemukan bahwa sebagian besar atau 53\% dari partisipan penggemar K-pop di Surabaya ini berada pada tahap intense-personal dan sebanyak 15,9\% pada tahap borderlinepathological kemudian sisanya pada tahap entertainment-social.

Arnett menyatakan bahwa dewasa awal atau emerging adult adalah individu yang berusia 18-25 tahun (Santrock, 2011). Individu pada tahap perkembangan ini diasumsikan telah menuntaskan tugas perkembangan remaja yaitu telah sukses membentuk identitas jati diri dan mencapai autonomi, sehingga pada tahapan ini individu dituntut untuk fokus pada tugas selanjutnya yaitu mempersiapkan diri untuk mengemban peran baru dalam kehidupan seperti mempersiapkan diri untuk mencari jenjang karir yang tepat, memilih gaya hidup yang ingin dijalani apakah melajang atau menikah dan tugas perkembangan dewasa awal lainnya yang fokus pada pekerjaan dan cinta (Santrock, 2011). 
Celebrity worship pada dasarnya memiliki dampak positif pada penggemar seperti menginspirasi penggemar untuk belajar hal baru karena terinspirasi oleh selebriti favoritnya contohnya belajar musik atau belajar akting (Boon \& Lomore, 2001). Dampak yang negatif juga dapat ditimbulkan oleh celebrity worship yang berlebihan terutama pada tahap intense-personal dan borderline-pathological. Dampak negatif yang muncul seperti kurang produktif (Aini dkk., 2019), sulit untuk mandiri atau menentukan tujuan hidup (Nurohmah \& Prakoso, 2019), bahkan kegemaran yang berlebihan pada K-pop dapat membuat individu melakukan tindakan melukai diri sendiri (Rojek, 2012). Melihat dampak negatif ini maka penelitian ini akan berfokus pada 2 tahap obsesif celebrity worship yaitu intense-personal dan borderline-pathological.

Pada dasarnya ada beberapa faktor yang menyebabkan celebrity worship pada seseorang seperti karisma dan daya tarik fisik selebriti K-pop, kemampuan selebriti dalam bermusik, dan adanya kedekatan budaya (Chao dan Joo-Yeun, 2013 dalam Azzahra \& Ariana, 2021; Cahyani \& Purnamasari, 2019). Pada beberapa penelitian, ditemukan beberapa faktor yang dapat menyebabkan celebrity worship. Penelitian McCutcheon dkk. (2002) menemukan bahwa kegagalan membentuk identitas pada masa remaja akan menyebabkan seseorang melakukan celebrity worship sebagai upaya dalam membangun identitasnya. Kecanduan juga dikatakan dapat menjadi penyebab celebrity worship oleh penelitian Shofa (2017) dimana pada penelitiannya, Shofa (2017) menemukan bahwa dewasa awal yang sudah melakukan aktivitas menyukai selebriti sejak remaja akan mengalami kecanduan dan sulit berhenti sehingga menyebabkan celebrity worship saat dewasa awal. Hubungan buruk dengan orang lain juga menyebabkan seseorang lebih memilih untuk menjalin hubungan dengan selebriti. Pada masa dewasa awal salah satu tugasnya adalah intimacy vs isolation dimana orang yang terisolasi akan menjadikan hubungan dengan selebriti sebagai alternatif hubungan (Ashe \& McCutcheon, 2001). Selanjutnya, harga diri rendah dikatakan dalam penelitian Sitasari dkk., (2019) menyebabkan melakukan celebrity worship karena takut mendapat penolakan dari lingkungan sekitarnya. Kesejahteraan psikologis yang rendah juga dikatakan dapat menjadi faktor penyebab celebrity worship pada seseorang (Maltby dkk., 2001). Pada penelitian ini penulis memilih harga diri dan kesejahteraan psikologis sebagai variabel bebas.

Harga diri adalah evaluasi positif atau negatif seseorang pada dirinya sendiri bagaimana individu menilai diri sendiri (Rosenberg, 1965). Individu dengan harga diri tinggi memiliki karakteristik seperti dapat menghargai diri sendiri, merasa dirinya cukup baik, dan merasa dirinya berharga. Sebaliknya, seseorang dengan harga diri rendah memiliki perasaan bahwa dirinya tidak berharga dan tidak layak, sehingga mereka tidak menyukai diri sendiri (Abdel-Khalek, 2016).

Terdapat beberapa penelitian yang berhasil menemukan hubungan antara harga diri dan celebrity worship. Penelitian yang dilakukan Reeves, Baker, \& Truluck (2012) menemukan bahwa seseorang yang hidup dalam individualisme cenderung merasa kosong dan memiliki harga diri rendah yang dapat menjadi prediktor munculnya celebrity worship pada seseorang. Pada penelitian lainnya yang dilakukan Sitasari dkk. (2019) di Indonesia menemukan bahwa harga diri memiliki hubungan negatif dengan celebrity worship. Seseorang dengan harga diri rendah cenderung merasa takut akan mendapatkan penolakan sosial dan mengalami kesulitan ketika dirinya dihadapkan dengan penolakan dari sekitarnya, sehingga individu melakukan celebrity worship sebagai alternatif dalam menjalin hubungan (Sitasari dkkl., 2019). Harga diri rendah cenderung membuat seseorang merasa tidak layak untuk memiliki hubungan dengan orang lain sehingga meningkatkan tendensi untuk melakukan celebrity worship (Kusuma \& Yuliawati, 2013). Hal ini didukung juga oleh penelitian lainnya oleh Rosida (2019) yang juga menemukan hubungan negatif antara harga diri dan celebrity worship. Penelitian Kusuma dan Yuliawati (2013) tidak dapat menemukan hubungan harga diri dan celebrity worship. Akibat dari adanya 
perbedaan hasil penelitian terkait kedua variabel ini maka penulis ingin meneliti sendiri untuk membuktikan hipotesis terkait pengaruh harga diri terhadap celebrity worship.

Selain harga diri, kesejahteraan psikologis juga dikatakan dapat menjadi anteseden dari celebrity worship. Kesejahteraan psikologis yang rendah dapat menyebabkan individu tidak dapat koping dengan kehidupannya sehingga melakukan celebrity worship untuk melarikan diri sejenak dari realita (Maltby, dkk., 2001). Kesejahteraan psikologis adalah konvergensi dari beberapa fungsi positif yang disatukan menjadi pondasi kesejahteraan psikologis (Ryff, 2013). Konsep kesejahteraan psikologis menurut Ryff terdiri dari 6 dimensi yaitu self-acceptance (menerima diri sendiri secara positif), purpose in life (memiliki tujuan hidup yang ingin dicapai), positive relations with others (memiliki hubungan yang baik dengan orang lain), autonomy (mandiri), environmental mastery (dapat menguasai hal kompleks di lingkungan), dan personal growth (terus tumbuh dan berkembang seiring berjalannya waktu).

Beberapa penelitian terdahulu telah meneliti kaitan antara kesehatan mental dan celebrity worship seperti penelitian Maltby dkk. (2001) yang menemukan gejala kecemasan dan depresi pada celebrity worship tahap intense-personal dan borderline-pathological. Penelitian Zsila, Urbán, McCutcheon, dan Demetrovics (2019) menemukan bahwa gejala gangguan psikologis seperti depresi, kecemasan, paranoid, dan hostility membuat seseorang lebih mudah berfantasi dan terjerumus pada celebrity worship. Kemudian penelitian di Indonesia yang dilakukan oleh Nurohmah dan Prakoso (2019) pada penggemar K-pop menemukan bahwa kesejahteraan psikologis yang rendah berhubungan dengan celebrity worship yang tinggi.

Sejauh ini penelitian mengenai kesehatan mental dan celebrity worship umumnya meneliti gangguan psikologis seperti kecemasan dan depresi sebagai indikator kesejahteraan psikologis. Hal ini berkaitan erat dengan sejarah lama yang mengaitkan sehat secara mental ditandakan dengan ketidakhadiran gangguan psikologis (Fava, 2012). Kenyataannya, kesehatan mental tidak hanya soal terbebas dari gangguan psikologis, tapi juga kehadiran kesejahteraan psikologis itu sendiri. Bagaimana seseorang dapat memanfaatkan aspek-aspek positif dalam dirinya agar mereka siap dalam menghadapi tantangan kehidupan (Almedom \& Glandon, 2007 dalam Vázquez dkk., 2009). Maka dari itu, penelitian mengenai kesejahteraan psikologis dan celebrity worship yang fokus pada fungsi positif dirasa penting untuk dilakukan. Penulis berharap penelitian ini dapat menjadi kontribusi penulis terkait perkembangan ilmu terutama kajian kesejahteraan psikologis dan celebrity worship.

Kota Surabaya dipilih sebagai tempat penelitian oleh penulis karena melihat kepopuleran K-pop di Surabaya serta antusiasme penggemarnya. Surabaya pada tahun 2018 masuk ke dalam jajaran kota dengan penonton video K-pop terbanyak di seluruh dunia (Ghazwani, 2019). Surabaya juga merupakan kota dimana banyak komunitas K-pop berkembang salah satunya adalah komunitas KLOSS "Korean Lovers Surabaya Community" (Achmada \& Sadewo, 2014). Antusiasme penggemar di kota Surabaya juga dapat dilihat ketika penggemar K-pop menyambut pembukaan gerai kosmetik dari Korea Selatan yang dibuka pada tahun 2018 di salah satu pusat perbelanjaan di kota Surabaya. Salah satu situs berita mengabarkan penggemar di Surabaya rela mengantri berjam-jam untuk mendapatkan kesempatan memenangkan hadiah berupa merchandise yang berhubungan dengan salah satu selebriti Korea Selatan (Octove, 2018). Melihat hal ini, penulis kemudian merasa bahwa penelitian terkait penggemar K-pop di Surabaya perlu untuk dilakukan.

Berdasarkan argumentasi-argumentasi yang telah dijabarkan di atas, hipotesis penelitian ini adalah harga diri dan kesejahteraan psikologis memiliki pengaruh terhadap celebrity worship tahap intensepersonal dan borderline-pathological pada dewasa awal penggemar Korean Pop (K-pop) di Surabaya. 
Penelitian ini bertujuan untuk mengetahui apakah harga diri dan kesejahteraan psikologis berpengaruh terhadap celebrity worship tahap intense-personal dan borderline-pathological pada dewasa awal penggemar Korean Pop (K-pop) di Surabaya.

\section{Desain Penelitian}

\section{METODE}

Penelitian ini menggunakan pendekatan kuantitatif. Penelitian kuantitatif adalah penelitian yang datanya berupa angka yang dianalisis dengan metode statistika (Azwar, 2019). Jenis penelitian ini adalah penelitian eksplanatori yang bertujuan menjelaskan suatu fenomena (Neuman, 2014). Pengambilan data menggunakan metode survei dengan kuesioner secara daring. Desain penelitian ini dipilih karena sesuai dengan tujuan penelitian untuk mencari tahu pengaruh harga diri dan kesejahteraan psikologis terhadap celebrity worship.

\section{Partisipan}

Kriteria partisipan yang terlibat dalam penelitian ini adalah penggemar Korean Pop (K-pop) berusia 1825 tahun dan berdomisili di kota Surabaya. Dalam penelitian ini, teknik sampling yang digunakan adalah non probability sampling dengan metode purposive sampling. Metode purposive sampling dipilih karena terdapat karakteristik spesifik partisipan yang dibutuhkan dalam penelitian (Howitt \& Cramer, 2011). Dalam menentukan jumlah sample, peneliti menggunakan rumus $\mathrm{N}>140+\mathrm{m}$ (dimana $\mathrm{m}=$ jumlah variabel independen) sehingga jumlah partisipan minimal penelitian ini N $>106$ (Tabachnick \& Fidell, 2013). Sebelum mengisi kuesioner, partisipan terlebih dahulu diberikan informed consent yang berisikan informasi mengenai penelitian dan bukti kesediaan untuk berpartisipasi dalam penelitian.

Partisipan yang terlibat pada penelitian ini sejumlah 121 partisipan $\left(M_{\text {usia }}=20,4 ; S D_{\text {usia }}=1,74\right)$ di Surabaya. Partisipan sebagian besar terdiri dari 115 perempuan $(95,1 \%)$ dan 6 laki-laki $(4,9 \%)$. Mayoritas partisipan sejumlah 109 orang $(90,1 \%)$ telah menjadi penggemar K-pop sebelum menginjak usia 18 tahun dan 12 partisipan lainnya (9,9\%) menjadi penggemar K-pop setelah berusia 18 tahun. Berdasarkan frekuensi penggunaan internet, mayoritas partisipan sebanyak 80 orang $(66,1 \%)$ menggunakan internet lebih dari 6 jam/hari. Partisipan lainnya sebanyak 27 orang (22,3\%) menggunakan internet setidaknya 4-5 jam/hari, kemudian sisanya sebanyak 14 orang $(11,6 \%)$ menggunakan internet $1-2$ jam/hari.

\section{Pengukuran}

Pengukuran harga diri pada penelitian ini menggunakan Rosenberg Self-Esteem Scale (1965) yang telah diadaptasi ke dalam bahasa Indonesia oleh Rahman (2018). Skala ini terdiri dari 10 aitem dengan 4 pilihan jawaban skala Likert (1="sangat tidak setuju", 4="sangat setuju"), dengan koefisien reliabilitas yang baik $(\alpha=.853)$.

Kesejahteraan psikologis pada penelitian ini diukur dengan Psychological Well-being Scale milik Ryff \& Keyes (1995) yang telah diadaptasi oleh Rachmayani \& Ramdhani (2014). Skala asli dalam bahasa inggris terdiri dari 84 aitem, namun gugur menjadi 48 aitem setelah diadaptasi dan diuji coba pada partisipan di Indonesia. Alat ukur ini memiliki 5 pilihan jawaban skala Likert (1="sangat tidak setuju", $5=$ "sangat setuju"), dengan koefisien reliabilitas yang sangat baik $(\alpha=.912)$. 
Celebrity worship diukur dengan Celebrity Attitude Scale yang disusun oleh Maltby dkk. (2004) dan telah diadaptasi ke bahasa Indonesia oleh Malahayati (2018). Alat ukur terdiri dari 22 aitem dan 5 pilihan jawaban skala Likert (1="sangat tidak setuju", 5="sangat setuju"). Peneliti melakukan uji coba untuk melihat reliablitas alat ukur pada partisipan dengan usia 18-25 tahun. Skala ini terbagi ke dalam 3 sub skala yaitu entertainment-social $(\alpha=.770)$, intense-personal $(\alpha=.828)$, dan borderline-pathological $(\alpha=.551)$. Pada penelitian ini sub skala entertainment-social tidak ikut diteliti dalam analisis data.

Perolehan skor dari ketiga alat ukur dilakukan dengan cara menjumlah skor masing-masing dari setiap jawaban. Semakin tinggi total skor yang diperoleh maka mengindikasikan semakin tinggi juga tingkat harga diri, kesejahteraan psikologis dan celebrity worship, dan begitu sebaliknya semakin rendah jumlah skor maka menandakan semakin rendah harga diri, kesejahteraan psikologis, dan celebrity worship.

\section{Analisis Data}

Data melalui uji asumsi klasik sebelum pengujian hipotesis dengan uji regresi linear berganda. Uji asumsi klasik menunjukkan bahwa distribusi data normal dan ada hubungan linear, tidak menunjukkan multikolinearitas dan lolos uji homoskedastisitas. Setelah semua syarat uji asumsi klasik terpenuhi, uji regresi linear berganda untuk menguji hipotesis dapat dilakukan. Analisis data penelitian ini dilakukan dengan bantuan software IBM SPSS Statistics Version 25 for Windows dan Jamovi 1.6.15.

\section{HASIL PENELITIAN}

Berdasarkan hasil analisis deskriptif, didapatkan data yang menunjukan mayoritas partisipan memiliki tingkat harga diri yang sedang yaitu sebanyak 69 partisipan (57\%), sebanyak 34 partisipan $(28,1 \%)$ berada pada tingkat tinggi, dan pada tingkat rendah sebanyak 18 orang (14,9\%). Hasil analisis deskriptif penelitian juga menunjukan kebanyakan partisipan berada pada tingkat kesejahteraan psikologis sedang yaitu sebanyak 81 partisipan (66,9\%), selanjutnya pada tingkat tinggi sebanyak 34 partisipan $(28,1 \%)$, dan sisanya pada tingkat rendah 6 partisipan (5\%). Penormaan harga diri dan kesejahteraan psikologis menggunakan rumus kategorisasi norma hipotetik (Azwar, 2018). Kemudian, untuk celebrity worship, sebanyak 107 partisipan (88,5\%) berada pada tahap intense-personal dan sisanya 14 partisipan $(11,5 \%)$ berada pada tahap borderline-pathological. Kategori celebrity worship menggunakan norma yang dibuat oleh Maltby dkk. (2004).

Hasil analisis regresi linear berganda antara harga diri dan kesejahteraan psikologis terhadap celebrity worship pada sub skala intense-personal menunjukkan hasil yang tidak signifikan $(F(2,104)=0,878$; $\left.p>0,005 ; R^{2}=0,017\right)$. Harga diri dan kesejahteraan psikologis hanya dapat menyumbang pengaruh sebesar $1,7 \%$ pada celebrity worship intense-personal. Penulis juga melakukan uji nilai $t$ untuk melihat pengaruh harga diri dan kesejahteraan psikologis secara parsial. Harga diri $(B=0,46 ; S E=0,054 ; t=0,854$; $p>0,005)$ tidak memiliki pengaruh signifikan terhadap celebrity worship intense-personal. Kesejahteraan psikologis $(B=0,001 ; S E=0,010 ; t=0,057 ; p>0,005)$ juga tidak menunjukkan pengaruh signifikan terhadap celebrity worship tahap intense-personal.

Kemudian, hasil analisis regresi linear berganda yang kedua dilakukan untuk melihat pengaruh harga diri dan kesejahteraan psikologis terhadap celebrity worship borderline-pathological. Hasil yang diperoleh $\left(F(2,11)=0,295 ; p>0,005 ; R^{2}=0,051\right)$ menunjukkan variabel harga diri dan kesejahteraan psikologis tidak berpengaruh signifikan terhadap celebrity worship borderline-pathological. Kedua variabel X dapat memprediksi 5,1\% dari variabel celebrity worship borderline-pathological. Pada uji 
nilai $t$, harga diri $(B=-0,040 ; S E=0,110 ; t=-0,360 ; p>0,005)$ tidak memiliki pengaruh signifikan dalam menjelaskan celebrity worship tahap borderline-pathological. Kesejahteraan psikologis $(B=-0,004$; $S E=0,026 ; t=-0,162 ; p>0,005)$ juga tidak memiliki pengaruh signifikan pada celebrity worship tahap borderline-pathological.

\section{DISKUSI}

Pada penelitian ini, penulis memiliki tujuan untuk menguji apakah ada pengaruh antara harga diri dan kesejahteraan psikologis terhadap celebrity worship tahap intense-personal dan borderline-pathological pada dewasa awal penggemar Korean pop (K-pop) di Surabaya. Penulis melakukan analisis statistik uji regresi linear linear berganda untuk menguji hipotesis penelitian. Setelah melakukan analisis statistik yang dibutuhkan, penulis mendapatkan hasil bahwa harga diri dan kesejahteraan psikologis secara simultan tidak memiliki pengaruh yang signifikan terhadap celebrity worship. Penulis juga melakukan uji nilai t untuk melihat pengaruh harga diri dan kesejahteraan psikologis secara parsial terhadap celebrity worship. Setelah diuji, kedua variabel bebas juga tidak memiliki pengaruh yang signifikan. Maka dapat disimpulkan baik secara simultan maupun parsial, harga diri dan kesejahteraan psikologis tidak memiliki pengaruh terhadap celebrity worship.

Hasil ini tentu berbeda dengan hipotesis awal yang penulis yang menduga harga diri yang rendah dapat menyebabkan celebrity worship karena seseorang merasa tidak berharga dan takut mendapat penolakan dari lingkungan sosialnya. Hasil ini juga tidak mendukung penelitian sebelumnya seperti Rosida (2019). Perbedaan ini diduga karena partisipan pada penelitian sebelumnya adalah perempuan sedangkan penelitian ini dilakukan pada laki-laki dan perempuan. Menurut Ancok dkk. (1988 dalam Ghufron \& Risnawita, 2012) perempuan memang memiliki harga diri yang lebih rendah dari laki-laki sehingga perempuan memiliki kemungkinan untuk melakukan celebrity worship akibat harga diri yang rendah, sehingga hubungan antara kedua variabel dapat ditemukan. Partisipan pada penelitian ini juga memiliki harga diri yang baik pada kategori sedang dan tinggi. Individu dengan harga diri yang baik dapat membangun hubungan yang baik dengan orang lain sehingga tidak perlu melakukan celebrity worship sebagai alternatif (Sitasari dkk., 2019).

Meskipun penelitian ini tidak mendukung hipotesis, tetapi penelitian ini mendukung sebagian hasil penelitian Kusuma dan Yuliawati (2013) yang tidak menemukan hubungan antara harga diri dan celebrity worship pada tingkat intense-personal. Kusuma dan Yuliawati berpendapat hal ini terjadi karena aitem-aitem pada alat ukur Celebrity Attitude Scale terlalu umum dengan kegiatan sehari-hari sehingga kurang memiliki implikasi pada harga diri.

Kesejahteraan psikologis juga tidak memiliki pengaruh yang signifikan terhadap celebrity worship. Hasil ini berbeda dengan hipotesis awal dan penelitian-penelitian sebelumnya seperti Maltby dkk. (2001), Nurohmah \& Prakoso (2019) dan Zsila dkk. (2019). Perbedaan hasil ini diduga karena pada penelitian sebelumnya, gangguan psikologis seperti depresi, kecemasan, paranoid, dan hostility diukur sebagai indikator kesejahteraan psikologis sedangkan pada penelitian ini penulis lebih fokus pada aspek-aspek positif dari Ryff (2013) sebagai pondasi kesejahteraan psikologis dalam penelitian ini.

Pada penelitian sebelumnya Maltby dkk. (2001) mengatakan bahwa kesejahteraan psikologis yang buruk menyebabkan seseorang melakukan celebrity worship karena tidak dapat koping dengan kehidupan. Berdasarkan hasil penelitian, partisipan pada penelitian ini berada pada kategori kesejahteraan psikologis yang baik. Individu dengan kesejahteraan yang baik cenderung merasa optimis, positif, dan mampu koping lebih baik dengan kehidupan (Taylor dkk., 2000 dalam Vázquez, 
dkk., 2009) sehingga partisipan penelitian ini tidak membutuhkan celebrity worship sebagai pelarian dari kesejahteraan psikologis yang rendah.

Beberapa faktor diluar kedua variabel bebas yang tidak diteliti dalam penelitian ini diduga menjadi penyebab celebrity worship pada partisipan penelitian. Faktor pertama adalah jenis kelamin. Partisipan pada penelitian ini didominasi oleh perempuan, Zsila dkk. (2019) mengatakan perempuan memang lebih menyukai selebriti secara intens dari dunia hiburan, sedangkan laki-laki lebih suka dari dunia olahraga (Frith, 1983 dalam Malahayati, 2018). Situasi yang tidak ideal selama masa COVID-19 juga dapat menyebabkan celebrity worship dimana pada masa ini individu banyak menghabiskan waktu di rumah dan merasa jenuh sehingga menggunakan selebriti sebagai cara mengatasi kejenuhannya (Jarzyna, 2020). Faktor terakhir adalah karena budaya, teori Arnett (1994 dalam Santrock, 2011) memang mengatakan masa dewasa awal di mulai 18-25 tahun, akan tetapi beberapa ahli mengatakan di Indonesia masa dewasa awal baru dimulai usia 21 bahkan 22 tahun dan usia di bawah itu masih remaja akhir (Sukaesih, 2017). Mayoritas partisipan penelitian ini berusia di bawah 21 tahun sehingga pada masa remaja akhir ini individu memang sedang dalam masa menyukai selebriti dan menjadikan selebriti sebagai panutan dalam rangka menuntaskan tugas perkembangan yaitu membentuk identitas.

\section{SIMPULAN}

Berdasarkan serangkaian hasil penelitian yang telah dilakukan, dapat diambil kesimpulan bahwa harga diri dan kesejahteraan psikologis tidak memiliki pengaruh yang signifikan terhadap celebrity worship tahap intense-personal dan borderline-pathological pada dewasa awal penggemar Korean pop (K-pop) di Surabaya baik secara simultan maupun secara parsial.

Berdasarkan hasil penelitian, penulis memberi saran untuk penggemar K-pop agar senantiasa menjalin hubungan positif dengan orang lain disekitarnya agar terhindar dari celebrity worship yang berlebihan. Keluarga dan masyarakat juga hendaknya merangkul dan mendampingi penggemar K-pop. Bagi peneliti selanjutnya, dapat meneliti variabel selain harga diri dan kesejahteraan psikologis dan pengaruhnya pada celebrity worship.

\section{UCAPAN TERIMAKASIH}

Terima kasih kepada Allah SWT. dan semua pihak yang terlibat pada penelitian ini.

\section{DEKLARASI POTENSI TERJADINYA KONFLIK KEPENTINGAN}

Nada Nur Zahra dan Primatia Yogi Wulandari tidak bekerja, menjadi konsultan, memiliki saham, atau menerima dana dari perusahaan atau organisasi manapun yang mungkin akan mengambil untung dari diterbitkannya naskah ini.

\section{PUSTAKA ACUAN}

Abdel-Khalek, A. M. (2016). Introduction to the Psychology of Self-Esteem. https://www.researchgate.net/publication/311440256_Introduction_to_the_Psychology_of_selfesteem

Achmada, L., \& Sadewo, F. S. (2014). POLA PERILAKU KONSUMTIF PECINTA KOREA DI KOREA LOVERS

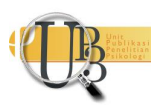


SURABAYA COMMUNITY (KLOSS COMMUNITY). Paradigma, 02(03), 1-7. https://jurnalmahasiswa.unesa.ac.id/index.php/paradigma/article/view/9407/9315

Aini, W. Q., Rahayu, M. S., \& Khasanah, A. N. (2019). Studi Deskriptif Psychological Well-Being pada Celebrity Worship Dewasa Awal di Komunitas EXO L Bandung. Prosiding Psikologi, 5(1). https://doi.org/http://dx.doi.org/10.29313/.v0i0.14127

Ashe, D. D., \& McCutcheon, L. E. (2001). Shyness, loneliness, and attitude toward celebrities. Current Research in Social Psychology, 6(9).

Azwar, S. (2018). Penyusunan Skala Psikologi (II). Pustaka Pelajar.

Azwar, S. (2019). Metode Penelitian Psikologi (2nd ed.). Pustaka Pelajar.

Azzahra, M. S., \& Ariana, A. D. (2021). Psychological Wellbeing Penggemar K-Pop Dewasa Awal yang Melakukan Celebrity Worship. Buletin Riset Psikologi dan Kesehatan Mental, 1(1), 137-148. https://doi.org/http://dx.doi.org/10.20473/brpkm.v1i1.24729

Boon, S. D., \& Lomore, C. D. (2001). Admirer-celebrity relationships among young adults.. Human Communication Research, 27(3), 432-465. https://doi.org/10.1111/j.1468-2958.2001.tb00788.x

Cahyani, D., \& Purnamasari, Y. (2019). Celebrity Worship on Early Adult K-Pop Fangirling. 304(Acpch 2018), 167-170. https://doi.org/10.2991/acpch-18.2019.41

Fava, G. A. (2012). The clinical role of psychological well-being. World Psychiatry, 11(2), 102-103. https://doi.org/10.1016/j.wpsyc.2012.05.018

Ghazwani, S. A. (2019). Fanatisme Fandom A.R.M.Y. (Adorable Representative M.C. For Youth) Terhadap Boyband Korea Selatan, Bangtan Sonyeondan (BTS) Di Surabaya. Ilmu Politik Dan Komunikasi UNAIR, 4.

Ghufron, N. M., \& Risnawita, R. (2012). Teori-Teori Psikologi. Ar-Ruzz Media.

Howitt, D., \& Cramer, D. (2011). Introduction to Research Methods in Psychology (3rd ed.). Pearson Education Limited. https://doi.org/10.1067/mcm.2003.64

Jarzyna, C. L. (2020). Parasocial Interaction, the COVID-19 Quarantine, and Digital Age Media. Human Arenas, 2020. https://doi.org/10.1007/s42087-020-00156-0

Jung, S. (2011). View of K-pop, Indonesian fandom, and social media. Transformative Works and Cultures, 8. https://journal.transformativeworks.org/index.php/twc/article/view/289/219

Kusuma, L., \& Yuliawati, L. (2013). Relationship Between Self-Esteem and Celebrity Worship on Late Adolescents. Anima Indonesian Psychological Journal, 28(4), 202-209.

Malahayati, S. (2018). Hubungan Antara kesepian dan celebrity worship pada Penggemar K-pop dewasa awal. Universitas Airlangga.

Maltby, J., Day, L., McCutcheon, L. E., Gillett, R., Houran, J., \& Ashe, D. D. (2004). Personality and coping: A context for examining celebrity worship and mental health. British Journal of Psychology, 95(4), 411-428. https://doi.org/10.1348/0007126042369794

Maltby, J., Houran, J., \& McCutcheon, L. E. (2003). A clinical interpretation of attitudes and behaviors associated with celebrity worship. Journal of Nervous and Mental Disease, 191(1), 25-29. https://doi.org/10.1097/00005053-200301000-00005

Maltby, J., McCutcheon, L. E., Ashe, D. D., \& Houran, J. (2001). The Self-Reported Psychological Well-Being

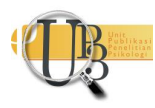


of Celebrity Worshippers. North American Journal of Psychology, 3(3), 441. https://www.researchgate.net/profile/Lynn-Mccutcheon/publication/233858367_The_SelfReported_Psychological_Well-

Being_of_Celebrity_Worshippers/links/5a0b0a970f7e9b0cc0251ca7/The-Self-Reported-

Psychological-Well-Being-of-Celebrity-Worshippers.pdf

Mccutcheon, L. E., Lange, R., \& Houran, J. (2002). Conceptualization and measurement of celebrity worship. British Journal of Psychology, 67-87.

Neuman, W. L. (2014). Basics of Social Research: Qualitative \& Quantitative Approaches (3rd ed.). Pearson.

Nurohmah, Y. F., \& Prakoso, H. (2019). Hubungan Psychological well being Dan Celebrity worship Pada Anggota Fansclub EXO Di Bandung. Prosiding Psikologi, 5(1), 181-186.

Octove, D. (2018, May 10). Gara-Gara Ini, Antrean Kunjungan Grand Opening Nature Republic TP 6 Surabaya Sampai 4,5 Jam. Surya. https://surabaya.tribunnews.com/2018/05/10/gara-gara-iniantrean-kunjungan-grand-opening-nature-republic-tp-6-surabaya-sampai-45-jam

Rachmayani, D., \& Ramdhani, N. (2014). Adaptasi Bahasa dan Budaya Skala Psychological Well-Being. PROCEEDING Seminar Nasional Psikometri, May 2014, 253-268.

Rahman, N. A. (2018). Pengaruh self-esteem terhadap Employability skills pada Mahasiswa dengan Status Kepengurusan dan Lama Waktu Mengikuti Unit Kegiatan Mahasiswa sebagai Variabel Moderator. Universitas Airlangga.

Reeves, R. A., Baker, G. A., \& Truluck, C. S. (2012). Celebrity Worship, Materialism, Compulsive Buying, and the Empty Self. Psychology \& Marketing, 29(9), 674-679. https://doi.org/10.1002/mar

Rojek, C. (2012). Fame Attack: The Inflation of Celebrity and Its Consequences. Bloomsbury. https://doi.org/10.1177/0094306115570271qq

Rosenberg, M. (1965). Society and the adolescent self-image. In Society and the Adolescent Self-Image. Princeton University Press. https://doi.org/10.2307/2575639

Rosida, A. (2019). Hubungan Self-Esteem dan Kesepian dengan Celebrity Worship pada Wanita Dewasa Awal Penggemar K-Pop. Universitas Airlangga.

Ryff, C. D. (2013). Psychological well-being revisited: Advances in the science and practice of $\begin{array}{llll}\text { eudaimonia. Psychotherapy and } & \text { Psychosomatics, }\end{array}$ https://doi.org/10.1159/000353263

Ryff, C. D., \& Keyes, C. L. M. (1995). The Structure of Psychological Well-Being Revisited. Journal of Personality and Social Psychology, 69(4), 719-727. https://doi.org/10.1037/0022-3514.69.4.719

Santrock, J. (2011). Life-span Development (Thirteenth). McGraw-Hill.

Shim, D. (2006). Hybridity and the rise of Korean popular culture in Asia. Media, Culture and Society, 28(1), 25-44. https://doi.org/10.1177/0163443706059278

Shofa, M. (2017). Gambaran Psikologis Celebrity Worship pada Dewasa Awal (Studi Kasus Mahasiswa Penggemar Korean Pop). Universitas Islam Negeri Maulana Malik Ibrahim.

Sitasari, N., Rozali, Y., Arumsari, A., \& Setyawan, D. (2019). Self-Esteem And Celebrity Worship In Social Network Bollywood Mania Club Indonesia Members In Jakarta. Proceedings of the 1st International Conference on Business, Law And Pedagogy, ICBLP 2019. 
https://doi.org/http://dx.doi.org/10.4108/eai.13-2-2019.2285982

Sukaesih, T. (2017). Pendidikan Keimanan Bagi Usia Dewasa Awal Menurut Perspektif Islam. UIN Raden Intan Lampung.

Tabachnick, B. G., \& Fidell, L. (2013). Using Multivariate Statistics (6th Edition). Pearson. https://doi.org/10.1037/022267

Vázquez, C., Hervás, G., Rahona, J., \& Gómez, D. (2009). Psychological well-being and health. Contributions of positive psychology. Annuary of Clinical and Health Psychology, 5(December), 1527.

Widjaja, A. K., \& Ali, M. M. (2015). Gambaran Celebrity Worship Pada Dewasa Awal di Jakarta. Humaniora, 6(1), 21-28.

Zsila, Á., Urbán, R., McCutcheon, L. E., \& Demetrovics, Z. (2019). A path analytic review of the association between psychiatric symptoms and celebrity worship: The mediating role of maladaptive daydreaming and desire for fame. Personality and Individual Differences, 151(July), 109511. https://doi.org/10.1016/j.paid.2019.109511 